\title{
Clinical and genetic findings of two cases with Apert syndrome
}

\author{
Francisco Cammarata-Scalisi ${ }^{*}$, Elanur Yilmaz ${ }^{2}$, Michele Callea ${ }^{3}$, Andrea Avendaño $^{1}$, Ercan Mıhçı ${ }^{4}$ and \\ Ozgul M. Alper ${ }^{2}$ \\ ${ }^{1}$ Unit of Medical Genetics, Department of Pediatrics, Faculty of Medicine, University of The Andes, Mérida, Venezuela; ${ }^{2}$ Department of Medical \\ Biology and Genetics, Akdeniz University Medical School, Antalya, Turkey; ${ }^{3}$ Unit of Dentistry, Bambino Gesù Children's Hospital, IRCCS, Rome, Italy; \\ ${ }^{4}$ Department of Pediatric Genetics, Akdeniz University Medical School, Antalya, Turkey
}

\begin{abstract}
Background: Craniosynostosis is described as the premature fusion of cranial sutures that belongs to a group of alterations which produce an abnormal phenotype. Case report: Two unrelated female patients with clinical findings of Apert syndrome-characterized by acrocephaly, prominent frontal region, flat occiput, ocular proptosis, hypertelorism, down-slanted palpebral fissures, midfacial hypoplasia, high-arched or cleft palate, short neck, cardiac anomalies and symmetrical syndactyly of the hands and feet-are present. In both patients, a heterozygous missense mutation (c.755C>G, p. Ser252Trp) in the FGFR2 gene was identified. Conclusions: Two cases of Apert syndrome are described. It is important to recognize this uncommon entity through clinical findings, highlight interdisciplinary medical evaluation, and provide timely genetic counseling for the family.
\end{abstract}

Key words: Apert syndrome. Clinical. FGFR2 gene. c.755C>G, p.Ser252Trp. Genetic counseling.

\section{Hallazgos clínicos y genéticos de dos casos con síndrome de Apert}

\section{Resumen}

Introducción: Las craneosinostosis se describen como la fusión prematura de las suturas craneales y resultan un grupo de alteraciones que producen un fenotipo anormal. Caso clínico: En este informe de casos se presentan dos pacientes de sexo femenino no emparentadas con hallazgos clínicos del síndrome de Apert, caracterizado por acrocefalia, región frontal prominente, occipucio plano, proptosis ocular, hipertelorismo, fisuras palpebrales hacia abajo, hipoplasia mediofacial, paladar alto o hendido, cuello corto, cardiopatía congénita y sindactilia simétrica en manos y pies. En ambas pacientes se identificó una mutación cambio de sentido en heterocigosis (c.755C>G, p.Ser252Trp) en el gen FGFR2. Conclusiones: Se presentan dos casos de síndrome de Apert. Es importante reconocer a través de los hallazgos clínicos esta entidad infrecuente, resaltar la evaluación médica interdisciplinaria y proporcionar un oportuno asesoramiento genético a la familia.

Palabras clave: Síndrome de Apert. Clínica. Gen FGFR2. c.755C>G, p.Ser252Trp. Asesoramiento genético.

Correspondence:

${ }^{*}$ Francisco Cammarata-Scalisi

E-mail: francocammarata19@gmail.com
Available online: 11-01-2019
Bol Med Hosp Infant Mex. 2019;76:44-48

www.bmhim.com 


\section{Introduction}

Craniosynostosis is characterized by a premature sutural fusion that can occur as a sole entity or associated with other anomalies. As a syndrome, craniosynostosis is a heterogeneous condition related to more than 180 syndromes $^{1}$. Apert syndrome (AS) (OMIM 101200) was first described in 1906 by Dr. Eugene Apert, a French pediatrician, who designed it as acrocephalosyndactyly type $\mathrm{I}^{2,3}$. Craniosynostosis occurs in approximately $1 / 65,000$ to 200,000 live births with Apert syndrome ${ }^{2,3-5}$, which represents $3 \%$ of all craniosynostosis. This syndrome affects equally male and female patients ${ }^{3,5}$. Two different types of mutations have been found on the fibroblast growth factor receptor-2 gene (FGFR2, OMIM 176943, NM_001144916.1) in several syndromic craniosynostoses, including AS. Inheritance pattern of AS is autosomal dominant, and over $98 \%$ of cases have de novo mutations ${ }^{2-7}$.

Clinical features of AS, including craniosynostosis ${ }^{3}$, are characterized by bilateral coronal suture fusion $(\text { acrocephaly })^{2}$ with a diminished anteroposterior diameter, flat occiput ${ }^{3}$, and abnormal cranial base development $^{2}$, prominent forehead, hyperteleorism ${ }^{3,6}$, downward sloping palpebral fissures ${ }^{6}$, proptosis $^{3,6}$, strabismus $^{4}$, depressed nasal bridge ${ }^{3}$, midface hypoplasia $^{3,4,6}$, low-set ears ${ }^{8}$, a trapezoidal-shaped mouth ${ }^{6}$, prominent mandible ${ }^{3}$, high-arched or cleft palate ${ }^{3}$, bifid uvula $^{2}$, delay in dentition, abnormal and crowded dentition $^{3,6}$ and pharynx defects frequently result in airway compromise ${ }^{8}$, symmetrical syndactyly of the hands and feet $^{3,5,6}$, symphalangism and radio-humeral fusion. The multiple abnormalities of the central nervous alterations include hydrocephalus ${ }^{2}$, ventriculomegaly ${ }^{2,4}$, alterations of the septum pellucidum ${ }^{2}$, corpus callosum ${ }^{2,4}$, and limbic structures ${ }^{2}$. Additionally, cardiac, gastrointestinal, urogenital, vertebral anomalies ${ }^{4}$ and short stature have been reported ${ }^{4,5}$. Furthermore, psychomotor development may be delayed ${ }^{3,6}$, with variable degrees of neurocognitive impairment ${ }^{2,8}$; blindness and hearing loss $^{6}$ can be observed. A multidisciplinary approach is required for the management of this entity due to this multisystem involvement ${ }^{3}$.

In this work, we report two Venezuelan female patients with clinical features of AS with heterozygous mutations (c.755C>G; p.Ser252Trp) in the FGFR2 gene, with the objective of recognizing this uncommon entity through clinical findings, highlighting interdisciplinary medical evaluation, and providing timely genetic counseling for the family.

\section{Methods}

Both patients diagnosed with AS were clinically evaluated in the Unit of Medical Genetics, Department of Pediatrics, University of The Andes, Mérida, Venezuela. Diagnostic molecular genetic tests were performed in the Department of Medical Biology and Genetics, Akdeniz University Medical School, Antalya, Turkey, in concordance with the institutional review board protocols approved by the ethics committees under the most recent version of Helsinki Declaration. Signed informed consent was obtained from the parents of the patients.

Genomic DNA of the patients and the parents were isolated from peripheral blood samples for diagnostic molecular genetic analysis by a modified non-enzymatic method from Lahiri and Nurnberger ${ }^{9}$. Amplification of genomic DNA was performed using previously described primers and conditions in a standard polymerase chain reaction ${ }^{10}$. DNA sequencing analysis was performed using the Big Dye Terminator Kit v3.1 (Applied Biosystems) and an ABI 3130XL Genetic Analyzer (ABI Prism, USA). The sequencing data were compared with GenBank (NM_022976) sequences by using NCBI blast suite (https://blast.ncbi.nlm.nih.gov). Mutation nomenclature was done based on Human Genome Variations Guidelines.

\section{Case reports}

\section{Case 1}

A three-day-old newborn female patient with craniosynostosis and symmetric syndactyly of hands and feet. Healthy and non-consanguineous parents, a 27-year-old mother and a 24-year-old father. She was born at term at 38 weeks of gestation by vaginal delivery after a complicated pregnancy with urinary tract infection, which was treated. Weight at birth, $2,840 \mathrm{~g}$ (-1 standard deviation (SD)); length, $50 \mathrm{~cm}$ (-0.1 SD); head circumference, $38 \mathrm{~cm}$ ( $>97^{\text {th }}$ percentile). Apgar scores of 7 at 1 minute, and 9 at 5 minutes. No family history of similar alterations or any other congenital anomalies were reported.

Physical examination of the patient revealed abnormal acrocephaly, prominent frontal region, and flat occiput. She also had ocular proptosis, hypertelorism, and down-slanting palpebral fissures. In addition to these symptoms, she had midfacial hypoplasia, broad nasal root, depressed nasal bridge, thick nose with a bulbous tip, open mouth with crossbow-shaped lips and 

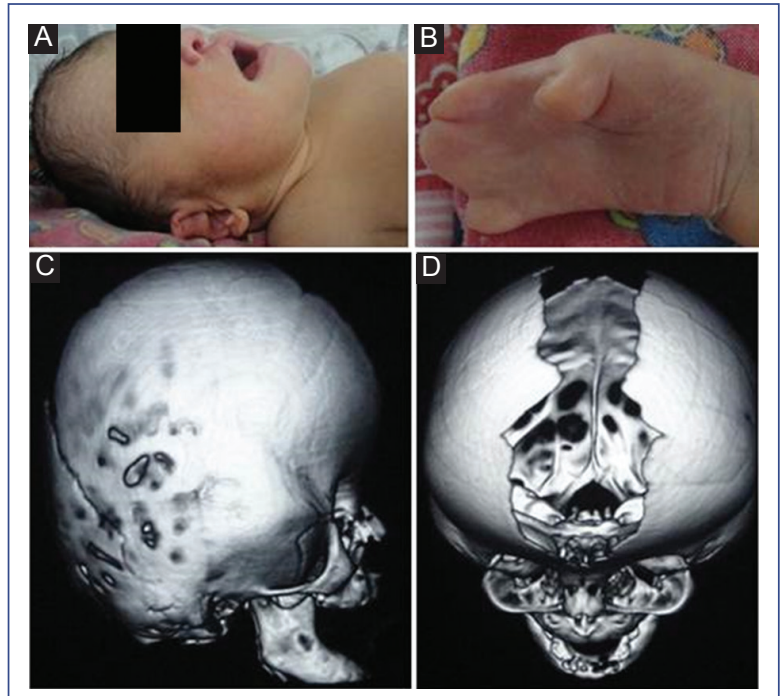

Figure 1. A. Acrocephaly, prominent frontal region, depressed nasal bridge, bulbous tip, open mouth, low ear implantation, overfolded helix, dysplasia of the auricle and short neck. B. Cutaneous syndactyly of the hand. C. Computed tomography of the skull in 3D shows diminished anteroposterior diameter. D. Complete closure of both coronal sutures and diastasis of the parietal and metopic sutures.

intraorally cleft soft palate; also, low ear implantation, overfolded helix, dysplasia of the auricle and short neck (Fig. 1A). She had symmetrical syndactyly of hands (Fig. 1B), feet and bilateral pes cavus.

The newborn screening tests results were normal. 3D-Computed tomography of the skull showed asymmetry with increased cross-sectional and diminished anteroposterior diameters. Complete closure of both coronal sutures and diastasis of the parietal and metopic sutures (Figs. 1C and 1D) were observed. Besides, facial hypoplasia and hypertelorism were evident, without other alterations. Transthoracic echocardiogram showed patent foramen oval and patent ductus arteriosus with subsequent successful closure. Abdominal ultrasound was normal. The molecular genetic analysis for exons IIIa and IIIC of FGFR2 gene (Fig. 2) revealed a heterozygous missense mutation (c.755C $>\mathrm{G}$; p.Ser252Trp).

\section{Case 2}

A two-month-old female patient with craniosynostosis and symmetric syndactyly of hands and feet. She was born at term at 40 weeks of gestation by cesarean delivery without complications. Healthy and non-consanguineous parents, a 23-year-old mother and a 24-year-old father. Weight at birth, 3,390 g (0.6 SD); length, $52 \mathrm{~cm}$ (2.1 SD); and head circumference, $37.8 \mathrm{~cm}$ $\left(>97^{\text {th }}\right.$ percentile). Apgar scores of 8 at 1 minute, and 9 at 5 minutes. No family history of similar alterations or any other congenital anomalies were reported.

As a result of physical examination, abnormal acrocephaly, prominent frontal region and flat occiput, ocular proptosis, hypertelorism, and down-slanting palpebral fissures were observed. Additionally, the patient showed midfacial hypoplasia broad nasal root, depressed nasal bridge, thick nose with a bulbous tip, open mouth with crossbow-shaped lips and intraorally high arched palate. Short neck and symmetrical syndactyly of hands and feet were also determined (Fig. 3).

The newborn screening tests results were normal. Transthoracic echocardiogram showed large ostium secundum atrial septal defect with moderate hemodynamic repercussion and small muscular ventricular septal defect. Abdominal ultrasound was normal. Genetic analysis of the patient revealed a heterozygous mutation (c.755C>G; p.Ser252Trp) in the FGFR2 gene.

\section{Discussion}

Mutations in the FGFR2 gene can be found in several syndromic craniosynostoses, including Apert (OMIM 101200), Crouzon (OMIM 123500), Pfeiffer (OMIM 101600), Beare-Stevenson (OMIM 123790) and Jackson-Weiss (OMIM 123150) syndromes ${ }^{1,11}$. Genetic mutations in AS were discovered for the first time in 1995 by Wilkie, et al.2; they occur as a result of heterozygous mutations in FGFR2 gene located at 10q25.3-264,7, which encodes a tyrosine kinase receptor gene that regulates multiple cellular activities, such as cell growth, differentiation, and embryonic development ${ }^{13}$. Two adjacent missense mutations $-\mathrm{c} .755 \mathrm{C}>\mathrm{G}$ and c. $758 \mathrm{C}>\mathrm{G}$, resulting in p.Ser252Trp $(66 \%)$ and $p$. Pro253Arg (32\%) respectively $2,5,8,11,12,14$ —are related to AS. These mutations occur in a highly conserved region in the immunoglobulin-like extracellular subdomains of exon Illa of FGFR2 gene in $>98 \%$ of the cases of $A S^{8,11,14}$. The first mutation is tightly associated with a more severe craniofacial phenotype ${ }^{11,13}$ and cleft palate ${ }^{13}$, while the second is associated with more severe syndactyly ${ }^{11,13}$. Of the two cases reported here, only case 1 presented cleft palate. Other uncommon mutations in FGFR2 gene have been described in AS, such as c.756_758delGCCinsCTT ${ }^{15}$, c.755_757delCGCinsTCT ${ }^{16}$, c.755_756CG>TC, c,755_756CG>TT 17 , partial gene deletion, and Alu element insertion ${ }^{18}$. 


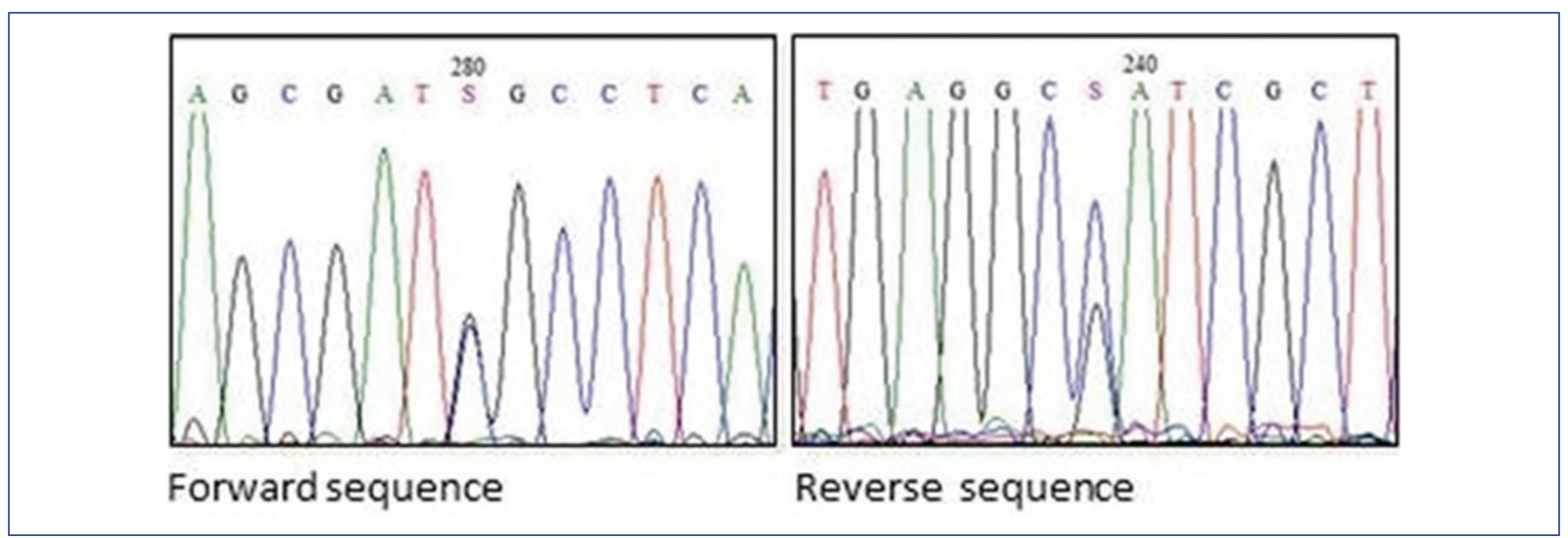

Figure 2. FGFR2 gene, forward and reverse sequences of exon 3a.

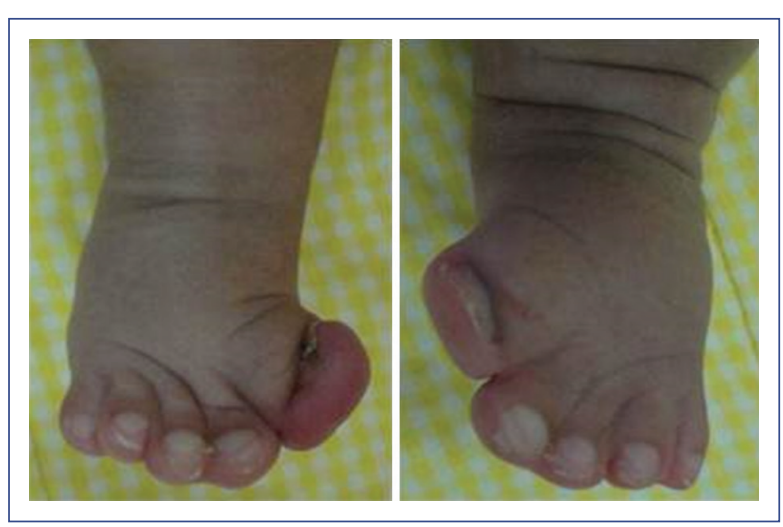

Figure 3. Syndactyly in both feet.

AS is an entity with an autosomal dominant inheritance pattern, with $98 \%$ of cases due to de novo mutations ${ }^{2}$. These causative mutations are transmitted in the paternal chromosome, which is why advanced paternal age could be a risk factor for this entity ${ }^{2,8,13}$. However, the parents of the two cases described in this article are not of advanced age.

Craniosynostosis is a group of various symptoms that exhibit distinctive clinical findings with a wide range of clinical manifestations; the severe ones could result in neonatal death. Syndromic craniosynostosis is the hereditary form of alterations of the skull associated with extracranial phenotypes such as the central nervous system, cardiac and limbs malformations ${ }^{8}$. Both of the present cases showed congenital heart disease. Therefore, it is suggested that the cardiovascular evaluation should be part of the medical studies. The significant phenotypic variability observed in AS is not only due to genetic alterations, but also the environmental or supplemental genetic factors ${ }^{2}$. Thus, a team of clinicians and medical geneticists is required for diverse evaluations ${ }^{1}$.

Prenatal diagnosis of AS is based on the ultrasonographic findings of abnormal skull shape, which include prematurely ossified coronal sutures, widely separated metopic suture, midfacial hypoplasia, and bony or cutaneous syndactyly of extremities ${ }^{19}$. The recurrence risk of having a child with this entity for an affected parent is of $50 \%{ }^{20}$. Since the presence of unaffected/ healthy parents, the condition described here is accepted as sporadic. The diagnosis is usually based on the physical features of the patients, and the molecular genetic analysis may be very helpful to confirm the diagnosis ${ }^{4}$.

In the case of a patient diagnosed with AS, an interdisciplinary medical evaluation consisting of assessments by Neurosurgery, Neuropediatrics, Stimulation Therapies, Psychology, Ophthalmology, Otorhinolaryngology, Maxillofacial Surgery, Cardiology, Orthopedics, and Medical Genetics is necessary. In the cases presented here, the molecular studies performed on the parents did not show the mutation. In cases with de novo mutations, the risk is $50 \%$ for the descendants of those affected and not for their siblings; however, germinal mosaicism cannot be rule out.

In conclusion, two cases of AS are presented in order to highlight the differences in clinical findings. These cases were recognized by the different treating physicians who intervened in their interdisciplinary evaluation. The interpretation of the FGFR2 mutations in patients with clinical features of syndromic craniosynostosis offers a significant benefit regarding prognosis, genetic counseling, and prenatal diagnosis. 


\section{Ethical disclosures}

Protection of human and animal subjects. The authors declare that no experiments were performed on humans or animals for this study.

Confidentiality of data. The authors declare that they have followed the protocols of their work center on the publication of patient data.

Right to privacy and informed consent. The authors have obtained the written informed consent of the patients or subjects mentioned in the article. The corresponding author is in possession of this document.

\section{Funding}

The authors declared that this study received no financial support.

\section{Acknowledgments}

We are thankful to the families of the patients for their participation. We also thank Burcu Coban Taner and Yasemin Arik Akkus from Akdeniz University for their kind technical assistance.

\section{Conflicts of interest}

The authors declare no conflict of interest.

\section{References}

1. Kunwar F, Tewari S, Bakshi SR. Apert syndrome with S252W FGFR2 mutation and characterization using Phenomizer: an Indian case report J Oral Biol Craniofac Res. 2017;7:67-71.

2. Breik O, Mahindu A, Moore MH, Molloy CJ, Santoreneos S, David DJ. Central nervous system and cervical spine abnormalities in Apert syndrome. Childs Nerv Syst. 2016;32:833-8.
3. Pettitt DA, Arshad Z, Mishra A, McArthur P. Apert syndrome: a consensus on the management of Apert hands. J Craniomaxillofac Surg. 2017; 45:223-31.

4. Kosiński $P$, Luterek $K$, Wielgoś $M$. Diaphragmatic hernia as an early ultrasound manifestation of Apert syndrome. Ginekol Pol. 2016;87:830.

5. Siminel MA, NeamȚu CO, DiŢescu D, ForȚofoiu MC, Comănescu AC, Novac MB, et al. Apert syndrome-clinical case. Rom J Morphol Embryol. 2017:58:277-80.

6. David DJ, Anderson P, Flapper W, Syme-Grant J, Santoreneos S, Moore M. Apert syndrome: outcomes from the Australian Craniofacial Unit's birth to maturity management protocol. J Craniofac Surg. 2016;27:1125-34.

7. Nur BG, Pehlivanoğlu S, Mıhçı E, Calışkan M, Demir D, Alper OM, et al. Clinicogenetic study of Turkish patients with syndromic craniosynostosis and literature review. Pediatr Neurol. 2014;50:482-90.

8. Ko JM. Genetic syndromes associated with craniosynostosis. J Korean Neurosurg Soc. 2016;59:187-91.

9. Lahiri DK, Nurnberger JI Jr. A rapid non-enzymatic method for the preparation of HMW DNA from blood for RFLP studies. Nucleic Acids Res. 1991;19:5444.

10. Wong LJ, Chen TJ, Dai P, Bird L, Muenke M. Novel SNP at the common primer site of exon IIla of FGFR2 gene causes error in molecular diagnosis of craniosynostosis syndrome. Am J Med Genet. 2001;102:282-5.

11. Fernandes MB, Maximino LP, Perosa GB, Abramides DV, Passos-Bueno MR, Yacubian-Fernandes A. Apert and Crouzon syndromes-cognitive development, brain abnormalities, and molecular aspects. Am J Med Genet A. 2016;170:1532-7.

12. Wilkie AO, Slaney SF, Oldridge M, Poole MD, Ashworth GJ, Hockley AD, et al. Apert syndrome results from localized mutations of FGFR2 and is allelic with Crouzon syndrome. Nat Genet. 1995;9:165-72.

13. Cammarata-Scalisi F, Ozen B, Chacín JA, Yavuz I, Callea M. Syndromic craniosynostosis: a review. J Int Dent Med Res. 2016;9:262-6.

14. Ibarra-Arce A, Ortiz de Zárate-Alarcón G, Flores-Peña LG, Martínez-Hernández F, Romero-Valdovinos M, Olivo-Díaz A. Mutations in the FGFR2 gene in Mexican patients with Apert syndrome. Genet Mol Res. 2015;14:2341-6.

15. Lumaka A, Mubungu G, Mukaba P, Mutantu P, Luyeye G, Corveleyn A, et al. A novel heterozygous mutation of three consecutive nucleotides causing Apert syndrome in a Congolese family. Eur J Med Genet. 2014; 57:169-73.

16. Oldridge M, Lunt PW, Zackai EH, McDonald-McGinn DM, Muenke M, Moloney DM, et al. Genotype-phenotype correlation for nucleotide substitutions in the Igll-Iglll linker of FGFR2. Hum Mol Genet. 1997:6:137-43.

17. Goriely A, McVean GA, van Pelt AM, O'Rourke AW, Wall SA, de Rooij DG, et al. Gain-of-function amino acid substitutions drive positive selection of FGFR2 mutations in human spermatogonia. Proc Natl Acad Sci USA. 2005;102:6051-6.

18. Bochukova EG, Roscioli T, Hedges DJ, Taylor IB, Johnson D, David DJ, et al. Rare mutations of FGFR2 causing Apert syndrome: identification of the first partial gene deletion, and an Alu element insertion from a new subfamily. Hum Mutat. 2009;30:204-11.

19. Wang YZ, Tsai HD, Hsieh CT. Prenatal diagnosis of a sporadic Apert syndrome by 3-D ultrasound and 3-D helical computerized tomography. Taiwan J Obstet Gynecol. 2017:56:571-2.

20. Kakutani H, Sato Y, Tsukamoto-Takakusagi $Y$, Saito F, Oyama A, lida J. Evaluation of the maxillofacial morphological characteristics of Apert syndrome infants. Congenit Anom (Kyoto). 2017;57:15-23. 